\title{
NOTE
}

\section{THE EFFEGT OF DAUNOMYGN} ON PHAGE INDUGTION

\author{
I. Gadó, Éva Boromissza \\ and I. HoRváth
}

Department of Microbiology, Research

Institute for Pharmaceutical Chemistry, Budapest, Hungary

(Received for publication May 2, 1969)

As it is known, daunomycin, an anticarcinogenic antibiotic described by Di MARco et al. ${ }^{1)}$, inhibits the synthesis of DNA and RNA (BARBIERI et $\left.a l .{ }^{2}\right)$ ), induces phage production in lysogenic cells (HeINemann and HowARD ${ }^{3)}$ ), but inhibits phage multiplication in the case of $T$ phage (PARISI and Soller ${ }^{4)}$ ). Its effect, however, on heat induced phage production was not yet studied.

It appeared from our preliminary experiments, that similarly to mitomycin $\mathrm{C}$ and UV irradiation, daunomycin in a concentration up to $80 \mu \mathrm{g} / \mathrm{ml}$ at $28^{\circ} \mathrm{C}$ has no phage inductive effect on Escherichia coli $\mathrm{K} 12$ ( $\Delta$ cI-857) thermoinducible lysogenic organism, harbouring an ind ${ }^{-}$mutant prophage. This condition made it possible to study the effect of daunomycin on thermoinduction without any interference caused by its own inductive effect.

An $E$. coli $\mathrm{K} 12$ ( $\Delta$ cI-875) culture grown for 16 hours at $28^{\circ} \mathrm{C}$ in complete medium (nutrient broth) was diluted into 9 volumes of fresh complete medium and was further incubated at $28^{\circ} \mathrm{C}$ for 2 hours. After washing twice with distilled water $5.10^{5}$ cells $/ \mathrm{ml}$ were suspended in complete medium or in the case of shift down condition in minimal medium of Davis and Mingrolit ${ }^{5)}$ supplemented with L-throeonine and L-leucine (20 $\mu \mathrm{g} / \mathrm{ml}$ each). Heat treatment was accomplished at 45 or $43^{\circ} \mathrm{C}$ in complete or minimal medium, respectively. Plaque assay was performed at $37^{\circ} \mathrm{C}$ after chloroform treatment and at $28^{\circ} \mathrm{C}$ from untreated culture on indicator strain E. coli C 600 (APPLEYARD ${ }^{6)}$ ). The number of plaques in the former case was regarded as the concentration of com- plete phages, whereas plaques on $28^{\circ} \mathrm{C}$ were counted as infective centers. The phage yield was determined as follows: thermoinduced cultures were diluted 400-fold into complete medium and after incubation for 100 minutes at $28^{\circ} \mathrm{C}$ the complete phage concentration was measured.

Daunomycin was a gift of Prof. F. ARCAMONE of Farmitalia, Milano, Italy, the strain of E. coli K 12 ( $\Delta$ cI-857) was kindly supplied by Prof. F. Јасов of the Institute Pasteur, Paris, France.

As it is known, the thermoinducible lysogenic $E$. coli strains can grow fairly well at $28^{\circ} \mathrm{C}$ and there is no spontaneous phage production from the strain mentioned above at this temperature. If the cells are incubated at $45^{\circ} \mathrm{C}$ in complete medium, the immunity substance (repressor) becomes inactivated and the vrophage detached due to this derepression. This process of induction has been completed in the whole population in 20 minutes, and can be measured the increase of infective centers and the sharp fall of viable cell count (Fig. 1). During a prolonged incubation at $45^{\circ} \mathrm{C}$, the vegetative cycle of phage production will start but then inhibited presumably at a later step, and, consequently a very low production of complete phages can be detected. At the same time, however, the production of proteins responsible for the lysis of cells was undisturbed, thus the lysis could take place prematurely decreasing the count of infective centers (Groman and Suzuni ${ }^{7)}$ ). When the induced culture was cooled to $28^{\circ} \mathrm{C}$ at 20 minutes, the production of complete phages could intensively start, giving a burst size of about 200 independently of the moment of cooling.

Daunomycin $(50 \mu \mathrm{g} / \mathrm{ml})$ in complete medium inhibited the steep decrease of viable cell count. It delayed to a slight extent the rise of infective centers, but the achieved level remained unchanged for a long time. As it was expected, daunomycin repressed strongly the production of complete phages but this inhibition proved to be reversible; a normal phage yield could be reached after the dilution of daunomycin. 
Fig. 1. Effect of daunomycin on thermoinduction in complete medium.

Viable count in control culture (a) and in the presence of $50 \mu \mathrm{g} / \mathrm{ml}$ daunomycin (b). Infective center count in control culture (c) and in the presence of $50 \mu \mathrm{g} / \mathrm{m} 1$ daunomycin (d). Complete phage production in cultures thermoinduced in the absence (e) or in the presence (f) of $50 \mu \mathrm{g} /$ $\mathrm{ml}$ daunomycin, after a 400-fold dilution into complete medium at different times and further incubation for 100 minutes (Values are multiplied according to dilutions). All cultures were incubated from 0 minute at $45^{\circ} \mathrm{C}$.

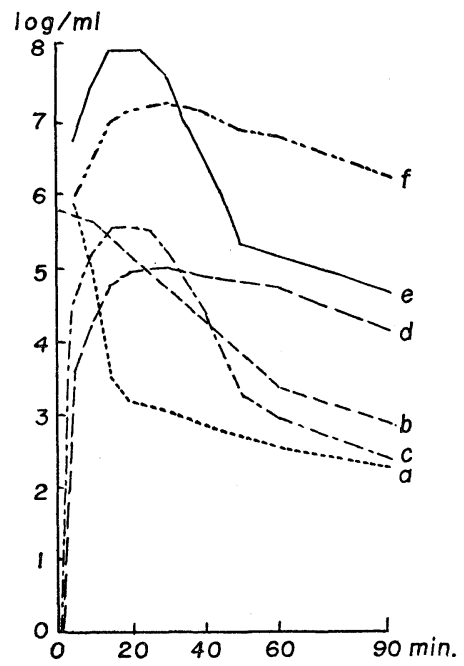

When an inoculum grow in complete medium was transferred into minimal medium (shift down condition) then the thermoinduction was carried out at $43^{\circ} \mathrm{C}$, the number of infective centers increased slower than in complete medium but the high level longer persisted. Only a small decrease of viable cell count could be observed. Daunomycin at a concentration of $20 \mu \mathrm{g} / \mathrm{ml}$ strongly delayed the increase of infective centers without any significant bactericid effect.

In shift down condition the experiments were sarried out at $43^{\circ} \mathrm{C}$ because daunomycin was bactericid at $45^{\circ} \mathrm{C}$ and this made the specificity of its action on phage induction questionable. This difference in temperature, however, did not cause any change in the thermoinduction of control cultures. On the other hand, thermoinduction was performed at $43^{\circ} \mathrm{C}$ also in complete medium with results similar to the above-mentioned ones all except the weak inhibition of phage production causing a second rise of infective centers. Therefore, the effect of daunomycin on the premature lysis was less observable.
Fig. 2. Effect of daunomycin on thermoinduction in shift down condition.

Viable count in control culture (a) and in the presence of $20 \mu \mathrm{g} / \mathrm{ml}$ daunomycin (b). Infective center count in control culture (c) and in the presence of $20 \mu \mathrm{g} / \mathrm{ml}$ daunomycin (d). All cultures were incubated from 0 minute on at $43^{\circ} \mathrm{C}$.

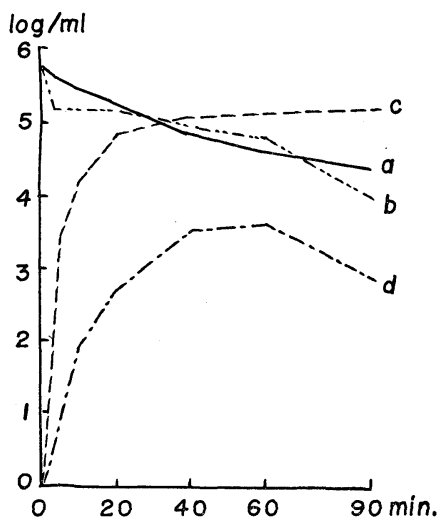

It appears from our experiments that in complete medium not only the production of complete phage but the decrease of infective centers in the course of prolonged incubation at $45^{\circ} \mathrm{C}$ can be inhibited by daunomycin. These effects of daunomycin are obviously the consequences of the inhibition of phage-DNA and/or RNA synthesis. It is more difficult to interprete the phenomenon which could especially be observed during the thermoinduction accomplished in the shift down condition. In such cases a marked delay was found in the increase of infective centers and this points to the fact that daunomycin inhibits also the derepression of prophage, the first phase of thermoinduction. According to numerous authors (Horiuchi and INOKUChi ${ }^{8)}, \mathrm{GrEEN}^{9)}$ and $\mathrm{Lieb}^{10)}$ ), derepression is caused by the thermolability of the repressor. A delay of this direct thermoinactivation by daunomycin is rather improbable. Our experiments refer to the possibility of derepression through an indirect way as it was supposed by Susman and $\mathrm{J}_{\mathrm{ACOB}^{11)}}{ }^{11}$, Wainfan et al. ${ }^{12)}$ and GoldTHWAIT and $\mathrm{JACOB}^{13)}$.

Comparable results to the aforesaid ones were obtained with hydroxyurea ${ }^{14)}$, in shift down condition a marked delay of derepression was proved. As hydroxyurea is a specific inhibitor of DNA synthesis (RosenKRANZ and LEVY ${ }^{15)}$ ), this refers to a role of 
DNA metabolism in the process of derepression, and thus daunomycin may also delay derepression by means of interfering with DNA metabolism.

\section{References}

1) Di Marco, A.; M. Gaetani, P. Orezzi, B. M. Scarpinato, R. Silvestrini, M. Soldati, F. Dasdia \& L. Valentini: Daunomycin, a new antibiotic of the rhodomycin group. Nature $201: 706 \sim 707,1964$

2) Barbieri, P.; A. Di Marco, R. Mazzoleni, M. Menozzi \& A. San Filippo: Azione della daunomycina sul metabolismo degli acdi nucleinici nell' E. coli B. Giorn. Microbiol. $12: 71 \sim 82,1964$

3) Heinemann, B. \& A. J. Howard : Effect of compounds with both antitumor and bacteriophage-inducing activities on Escherichia coli nucleic acid synthesis. Antimicr. Agents \& Chemoth.-1965 : 488 492, 1966

4) Parisi, B. \& A. Soller : Studies on the antiphage activity of daunomycin. Giorn. Microbiol. $12: 183 \sim 194,1964$

5) Davis, B. D. \& E. S. Mingroli : Mutants of Escherichia coli requiring methionine or vitamin $B_{12}$. J. Bact. $60: 17 \sim 28,1950$

6) Appleyard, R. K. : Segregation of new lysogene types during growth of a doubly lysogenic strain derived from Escherichia coil K 12 . Genetics $39: 440 \sim 452,1954$

7) Groman, N. B. \& G. Suzuki : Temperature and lambda phage reproduction. J. Bact.
$84: 431 \sim 437,1962$

8) Horiuchi, T. \& H. INokuchI : Temperaturesensitive regulation system of prophage lambda induction. J. Mol. Biol. 23 : 217 224, 1967

9) Green, M. H. : Inactivation of the prophage lambda repressor without induction. J. Mol. Biol. 16 : 134 148, 1966

10) LIEB, M. : Studies of heat-inducible lambda bacteriophage. I. Order of genetic sites and properties of mutant prophages. J. Mol. Biol. 16 : 149 163, 1966

11) Sussman, R. \& F. J J de repression thermosensible chez le bactériophage d'Escherichia coli. Compt. Rend. $254: 1517 \sim 1519,1962$

12) Wainfan, E.; P. R. SRinivasan \& E.Borek : Inhibition of tRNA methylylases in lysogenic organisms after induction by ultraviolet irradiation or by heat. J. Mol. Biol. 22 : 349 353, 1966

13) Goldthwait, D. \& F. JacoB : Induction mechanism of prophage development in lysogenic bacteria. Compt. Rend. $259: 661 \sim$ 664, 1964

14) Gadó, I.; É. Boromissza \& I. Horvath : Induction and multiplication of lambda phage. III. The effect of hydroxyurea on thermoinduction. Acta Microbiol. Acad. Sci. Hung. (in press)

15) Rosenkranz, H. S. \& J. A. Levy : Hydroxyurea : a specific inhibitor of deoxyribonucleic acid synthesis. Biochim. Biophys. Acta $95: 181 \sim 183,1965$ 